\title{
CEFD/UFSM - 50 ANOS - Uma trajetória pessoal Com a palavra, Cyro Knackfuss
}

\author{
CEFD/UFSM - 50 YEARS - A personal trajectory \\ With the word, Cyro Knackfuss \\ CEFD/UFSM - 50 AÑOS - Uma trayectoria personal \\ Com la palabra, Cyro Knackfuss \\ Vitor Paulo Camargo Goulart ${ }^{\mathrm{I}}$
}

\begin{abstract}
Resumo
De acordo com Mazo (1997), o Centro de Educação Física (CEF) da UFSM passou a funcionar em 14 de maio de 1970. Em 2020 o atual Centro de Educação Física e Desportos (CEFD) completa o 50 aniversário. Para resgatar parte da memória dos que testemunharam a história deste espaço de excelência na formação de professores de Educação Física, participamos deste momento especial, apresentando o testemunho de um dos professores com quem convivemos durante a vida acadêmica, com o qual compartilhamos a área de atuação na natação e cuja trajetória se confunde com a história do CEFD, o professor Dr. Cyro Knackfuss. Em uma entrevista o professor resgata sua trajetória de 46 anos no Centro, onde aborda sua chegada para estudar no curso, suas influências na Educação Física, a convivência com os professores pioneiros, o seu trabalho e contribuições para a profissão e as perspectivas.
\end{abstract}

Palavras-chave: História; Educação Física; CEFD; UFSM

\begin{abstract}
According to Mazo (1997), the then Centro de Educação Física (CEF) of the UFSM started to operate on May 14, 1970. In 2020 the current Centro de Educação Física e Desportos (CEFD) completes its 50th anniversary. To rescue part of the memory of those who witnessed the history of this space of excellence in the training of Physical Education teachers, we participated in this special moment, presenting the testimony of one of the teachers with whom we live during academic life, with whom we share the area of expertise in swimming and whose trajectory is confused with the history of CEFD, Professor Dr. Cyro Knackfuss. In an interview, the teacher retrieves his 46year trajectory at the Center, where he discusses his arrival to study the course, his influences on Physical Education, living with pioneer teachers, his work and contributions to the profession and perspectives for the future.
\end{abstract}

Keywords: History; Physical Education; CEFD; UFSM

\footnotetext{
${ }^{\text {I } U n i v e r s i d a d e ~ C o m u n i t a ́ r i a ~ d a ~ R e g i a ̃ o ~ d e ~ C h a p e c o ́ ~-~ U N O C H A P E C O ́ ~-~ E n d e r e c ̧ o: ~ S e r v i d a ̃ o ~ A n j o ~ d a ~ G u a r d a, ~ 295-D ~-~ E f a p i, ~ C h a p e c o ́ ~-~ S C, ~ C E P: ~ 89809-900 ~-~}$ e-mail: vitorpcg@desbrava.com.br
} 


\section{Resumen}

Según Mazo (1997), el entonces Centro de Educação Física (CEF) de la UFSM entró en funcionamiento el 14 de mayo de 1970. En 2020 el actual Centro de Educação Física e Desportos (CEFD) cumple 50 años. Para rescatar parte de la memoria de quienes presenciaron la historia de este espacio de excelencia en la formación de docentes de Educación Física, participamos en este momento especial, presentando el testimonio de uno de los docentes con los que convivimos durante la vida académica, con quien compartimos el área de especialización en la natación y cuya trayectoria se confunde con la historia del CEFD, el profesor Dr. Cyro Knackfuss. En entrevista, el docente recupera su trayectoria de 46 años en el Centro, donde comenta su llegada a estudiar el curso, sus influencias en Educación Física, convivencia con maestros pioneros, su trabajo y aportes a la profesión y perspectivas de futuro.

Palabras clave: Historia; Educación Física; CEFD; UFSM

\section{Introdução}

O Centro de Educação Física e Desportos (CEFD), uma das oito unidades da Universidade Federal de Santa Maria (UFSM), comemora em 2020 o seu 50ª aniversário. De acordo com Mazo (1997), o então Centro de Educação Física (CEF) idealizado pelo decano Milo Aita, passou a funcionar em 14 de maio de 1970, data em que foi proferida a aula inaugural pelo então diretor do Departamento de Desportos do Ministério de Educação e Cultura (MEC).

Para que não se percam dados relevantes, consideramos importante resgatar a memória histórica e ao mesmo tempo valorizar os sujeitos que são testemunhas de um processo de excelência na formação de professores de Educação Física ao longo de várias gerações.

A motivação desta produção se deve ao fato de que nos anos 80 frequentamos os espaços do CEFD durante nossa formação universitária, em um período que marcou positivamente nossa atividade profissional. Também tivemos como influência determinante o desenvolvimento de nossa atividade profissional no interior do estado de Santa Catarina na mesma modalidade de natação universitária que atua o entrevistado. Estes fatores aliados a abertura de um espaço na Kinesis, visando resgatar a memória do Centro de Educação Física e Desportos, nos levaram a buscar o testemunho de pessoas que contribuíram na formação de muitos professores que atualmente desenvolvem seu trabalho no país e fora dele.

Considerando estas variáveis, procuramos participar deste momento especial conhecendo um pouco mais a trajetória de vida de um docente com o qual tivemos a oportunidade de estudar na vida acadêmica, com o qual compartilhamos a área de atuação na natação e cuja trajetória se confunde com a história do CEFD, o professor Dr. Cyro Knackfuss. 
Nascido em Santa Maria-RS, Cyro tem mestrado e doutorado em Educação Física, sendo atuante no CEFD há 46 anos, período que compreende sua formação universitária por quatro anos e sua atividade como professor titular por mais 42 anos. Neste período jogou futebol profissional cuja influência o levou em 2007 a escrever o livro Cabeça-de-bagre: histórias do futebol, reunindo 23 crônicas sobre a história da modalidade em Santa Maria. Seu gosto pelo rádio o fez integrar o programa Radar Esportivo na Rádio Universidade. Seus estudos acadêmicos o levaram a pesquisar sobre as opções de Lazer e a influência dos espaços urbanos no movimento de crianças da comunidade Santa-mariense. Realizou cursos de qualificação e aperfeiçoamento na Espanha e na França. E hoje além das aulas na UFSM, participa de projetos de extensão para indivíduos com necessidades especiais, idosos, crianças e universitários.

Para atender o propósito desta produção, optamos por conversar com o professor sujeito da pesquisa coletando informações através de uma entrevista, na qual estabelecemos algumas questões norteadoras que serviram como fio condutor. Foram abordados temas como a aproximação com a Educação Física, a formação universitária, a trajetória no CEFD, o convívio com os pioneiros, a contribuição com a profissão e as perspectivas futuras para o Centro e a Educação Física brasileira.

\section{Entrevista}

\subsection{Fale sobre sua formação pessoal e influências que o levaram à Educação Física}

Eu acho que desde sempre fui professor de Educação Física. Considero que minha ida para a área foi um caminho natural, porque eu tive uma infância muito rica, com muitas oportunidades e muitas chances de movimento. Por outro lado, venho de uma família de esportistas. Meu pai foi jogador de futebol no Rio Grandense e no Internacional de Santa Maria e no Futebol Clube Santa Cruz e sempre nos estimulou a prática do esporte.

Na Educação Física também tenho uma irmã, a Marina Irani Knackfuss, conhecida como Gringa, que foi também professora no Centro de Educação Física e o meu saudoso irmão Irocy Guedes Knackfuss que era aluno de medicina e concomitantemente integrou a primeira turma do curso, inclusive tendo sido orador da primeira colação de grau se tornando se não o primeiro um dos primeiros médicos-professores da Educação Física do Rio Grande do Sul.

Associada a toda essa influência, fui nadador por muitos anos no Avenida Tênis Clube e jogador de futebol no Rio Grandense Futebol Clube onde avaliando a possibilidade de uma carreira futebolística, rapidamente percebi que não tinha muito futuro. 
Então, considero que isso tudo me levou naturalmente para o curso de Educação Física, em que pese o meu pai na melhor das intenções tenha tentado me levar para o curso de odontologia, que por ser uma área médica, achava que com isso eu seria mais feliz e poderia ganhar muito dinheiro. Mas graças a Deus fui reprovado no vestibular de odontologia e retomei então o caminho que precisava para ser feliz o de professor de Educação Física.

A oportunidade que tive como aluno do curso de Educação Física surgiu na cidade de Cruz Alta levado pelo professor Ruy Krebs que foi teu professor, meu professor, meu amigo, meu colega e era um dos fundadores do curso de Educação Física em Cruz Alta. Então, da metade do ano de 1972 até o final de 1973 cursei a faculdade na Universidade de Cruz Alta.

\subsection{Conte sobre sua chegada ao CEFD/UFSM, como era a realidade da época e relacione os professores que atuavam no período}

Em 1974 fui transferido para o CEF, que era como se chamava na época o Centro de Educação Física da UFSM. Fui o primeiro aluno transferido de uma outra faculdade para o curso de Educação Física. Isso só fiquei sabendo muitos anos depois.

E então comecei uma formação para licenciado em Educação Física, que era a titulação da época. Em função de equivalência curricular ao invés de fazer o curso em três anos, tive que fazer em quatro, mesmo que nunca tenha sido reprovado em exame algum, pois sempre fui um aluno que teve muita facilidade na Educação Física. Essa necessidade de equivalência curricular me deu uma experiência muito interessante, pois frequentava a aula com turmas de diferentes semestres do curso. Isso foi muito enriquecedor para mim e imediatamente após a minha formatura em agosto de 1976, fiz um curso de pósgraduação em nível de especialização em Biomecânica.

Ao chegar na UFSM em março de 1974, encontrei no curso os professores pioneiros do centro, aliás estou no CEFD desde a época do primeiro decano, o professor Milo Aita, até os dias de hoje. Naquela ocasião encontrei fundadores do centro, como o professor Jardini Tombesi, o professor Clóvis Monteiro Ávila, o professor Pedro Beno Lang, a professora Cecy Rubin e a professora Heloísa Pfeifer de Vasconcelos que carinhosamente nós chamávamos de "mãe". Também encontrei o Haimo Hartmuth Fenstersifer, o Jefferson Thadeu Canfield, o Ruy Jornada Krebs, o Floriano Dutra Monteiro e o Hélio Fuke que foram então da segunda turma de professores do CEFD. Portanto desde que estou no CEFD já se passaram quarenta e seis anos. Ou seja, dos cinquenta anos do centro, eu tenho aqui dentro, como professor e aluno quarenta e seis anos. 


\subsection{Fale sobre sua formação acadêmica (período, titulação e contexto) e áreas de atuação em geral}

No dia primeiro de maio, 1978, tive a alegria de ser convidado para fazer parte do corpo docente, do Centro de Educação Física e Desportos. Nessa trajetória de quarenta e seis anos tive a oportunidade de encontrar grandes mestres como Jurgen Friz Dieckert, professor da Alemanha que ficou muito tempo aqui, se tornou meu amigo e me influenciou bastante. Fiz um curso de recreação junto com saudoso professor Roque Moro e por muitos anos eu e o Roque fomos os únicos professores do centro com formação em recreação, embora eu nunca tenha atuado com essa área no CEFD. Fiz também um curso de especialização em tecnologia educacional na Pontifícia Universidade Católica do Rio Grande do Sul.

Mais tarde dando continuidade aos estudos, fiz mestrado, orientado pelo professor Aloísio Otávio Vargas Ávila. A temática da minha tese visava a transformação da barragem do rio Vacacaí na subida da serra, em um grande parque de lazer para Santa Maria. Minha tese foi desenvolvida no sentido de fazer da barragem um grande parque municipal. Ainda embora tenha se passado tanto tempo dessa tese que não progrediu junto as autoridades da cidade, eu ainda acredito que a transformação do parque da Barragem do Rio Vacacaí Mirim mudaria o perfil da cidade em termos de lazer. Hoje o grande foco de lazer de Santa Maria se dá nas dependências da Universidade Federal de Santa Maria, deixando a cidade muito pobre em opções de lazer.

Posteriormente eu tive um estágio na França, quando fiquei um ano e meio estudando na universidade da cidade de Clermont-Ferrand. Foi uma experiência riquíssima, não só sob o ponto de vista profissional, mas também cultural e pessoal.

Na volta ao Brasil iniciei o curso de doutorado em 1998. A temática era Chances e Restrições de Movimentos de Crianças moradoras na região central da cidade de Santa Maria. Onde nós explorávamos essa questão do movimento da criança e o impacto da televisão e das "urbes" sobre a infância, considerando essa problemática que incide sobre as pessoas e particularmente sobre as crianças.

2.4 Fale sobre a sua contribuição pessoal para o CEFD em suas áreas de atuação dentro e fora da universidade, em suas problemáticas de pesquisa e em sua concepção de mundo e da Educação Física 
A minha contribuição ao Centro de Educação Física e Desportes, desde que cheguei tem sido no sentido de ajudar na coordenação de jornadas acadêmicas e em comissões que tratam da progressão funcional de professores.

Também já atuei na comissão permanente de progressão funcional no Centro de Artes e Letras e atualmente desenvolvo um trabalho no Centro de Educação. Portanto sou um professor de Educação Física que participa de comissão no Centro de Educação da UFSM, valorizando o trabalho do CEFD.

Outra coisa que eu fiz aqui, foi contribuir com o professor Sérgio Carvalho, criador em 1981 do programa Radar Esportivo veiculado aos sábados nas rádios Universidade AM 800 e UniFM 107.9. Da mesma forma desenvolvo há mais de 20 anos um trabalho na rádio da Universidade, com intervenções em programas que abordam as mais diferentes temáticas. Falo de política, discorro pelo desporto e remeto a coisas do cotidiano, em um trabalho que sempre me deu muito prazer e sobre o qual estou atualmente reunindo as crônicas que fiz ao longo desses vinte anos com o objetivo de fazer uma publicação para apresentar a sociedade.

Também participei das atividades dos clubes esportivos universitários. Quando o decreto $\mathrm{n}^{\circ} 69450$ cancelou a obrigatoriedade dos clubes esportivos para os estudantes eu mantive um projeto de extensão na piscina, para os moradores da casa de estudantes da UFSM.

Acredito que contribui bastante para o CEFD. Em 1989 implantei o projeto de extensão denominado "Atividades Aquáticas para Portadores de Necessidades Especiais” o primeiro dessa natureza do CEFD. Por mais de vinte anos trabalhamos com crianças portadoras de necessidades especiais, através de um projeto interdisciplinar integrando o Centro de Educação Física com outros Centros de Ensino da Universidade. Como trabalho com natação há muito tempo e embora não seja especialista na área de portadores de necessidades especiais, busquei o apoio de professores e alunos de outros setores como o Centro de Artes e Letras e dos cursos de Odontologia e Fisioterapia para que a universidade prestasse um serviço de Natação Adaptada a essa população do entorno geográfico de Santa Maria. Neste período, nós desenvolvíamos atividades para crianças especiais aos sábados pela manhã. Atendíamos crianças de cidades como Caçapava do Sul, distante em torno de cem quilômetros de Santa Maria, bem como de São Sepé e Júlio de Castilhos. Isso auxiliou também na formação, não só dos futuros professores do curso de Educação Física, mas nas demais carreiras que trabalham conosco. Juntamente com a Educação Física, os cursos de Odontologia e Fisioterapia também prestavam serviço para as crianças que participavam do projeto, o que agregou na formação acadêmica dos estudantes. Ao longo desses anos vi o atendimento a crianças portadores aumentar consideravelmente na cidade de Santa Maria. 


\subsection{Fale sobre como você situa a contribuição do CEFD na história da Educação Física brasileira.}

Considero que o CEFD tenha contribuído muito para a Educação Física brasileira. Na época que comecei a trabalhar, o centro de Educação Física ostentava orgulhosamente o título de melhor curso de Educação Física do Brasil atraindo estudantes que vieram de vários países Sul-Americanos. Destaco um querido amigo, o professor Richard Manangon, que nos anos 80 veio do Equador, especialmente para o Centro de Educação Física buscando uma formação de qualidade no futebol. Ele saiu daqui com uma formação muito sólida e faz um grande sucesso em seu país, onde trabalhou em clubes de futebol profissional como a Liga Deportiva Universitária - L.D.U. que já foi campeã da Copa Libertadores. Atualmente é professor na Universidade Central do Equador em Quito, fazendo um trabalho de excelente nível.

Além da parte educacional, mais especificamente na parte esportiva, o CEFD já foi a meca do Handebol no país com o trabalho do professor Luiz Celso Giacomini que muito contribuiu na formação e aperfeiçoamento de jogadores da região de Santa Maria que serviram a seleção brasileira em diversos eventos internacionais. Trabalho este que continua sob a orientação dos professores Luiz Osório Portela e Cesar Geller.

Destaco também os convênios firmados com a Alemanha e a ida de professores do centro aos Estados Unidos em busca de aperfeiçoamento e qualificação, os quais deram um grande impulso ao centro de Educação Física. Acredito que exemplos como estes comprovam que o CEFD gozava de prestígio nacional e internacional.

2.6 O que você espera do CEFD para esse (atual) momento histórico do país e da Educação Física brasileira? Qual papel acredita que o CEFD deve desempenhar nessa conjuntura? Faça algumas considerações finais, caso necessário, em especial, rememorando os 50 anos do CEFD/UFSM

Em nossa cidade existe um problema muito sério. Há quem diga que a universidade não contribui ou mesmo que não a deixam contribuir com tudo aquilo que ela pode proporcionar. Existem empresários que dizem acertadamente que Santa Maria é uma cidade pujante, uma das setenta melhores do país para se viver, mas ela poderia estar melhor se as esferas de poder público estadual, municipal e federal dessem as mãos e caminhassem na mesma direção. Infelizmente o potencial que a universidade tem para emprestar à comunidade não é explorado de maneira conveniente. 
Historicamente, com as mudanças nas políticas do Ministério de Educação e Cultura - MEC e no Departamento de Educação Física e Desportos - DEFD/MEC, o CEFD sofreu alguns revezes e precisa retomar o patamar de elite universitária que merece estar. Entendo que uma das principais contribuições para que o centro tenha tido uma queda em seu prestígio, foi a aposentadoria precoce de mais de dez professores doutores do CEFD, os quais durante o governo Fernando Henrique Cardoso se afastaram preocupados com reformas em suas carreiras. Estes doutores foram prestar seus serviços de excelência profissional em outras universidades com a UDESC em Santa Catarina que passou a ter um papel destacadíssimo no Brasil.

Não sou um saudosista, mas vejo que o CEFD sempre teve professores com opiniões diversas, mas com um objetivo em comum, que era lutar pelo prestígio do centro de Educação Física, não só dentro da universidade, mas também no contexto social e comunitário. Considero que atualmente o centro perdeu um pouco deste objetivo comum e precisa reencontrar o seu caminho, porque tem potencial de contribuição muito grande para a comunidade e a Educação Física.

Espero sinceramente, que nesse ano quando comemoramos os cinquenta anos do Centro de Educação Física, a entrada de novos professores através dos concursos promovidos recentemente, levem o centro a recuperar o seu prestígio e os valores que fizeram do CEFD uma potência da Educação Física brasileira.

Mas essas coisas precisam de tempo para acontecer. Temos muitos professores oriundos de outros lugares. Muitos são jovens e precisam de tempo para amadurecer e entender o seu papel no CEFD e na Universidade Federal de Santa Maria. E como dizia Pablo Picasso... “A gente leva muito tempo para ser jovem...".

\section{Referências}

MAZO, J. História do Centro de Educação Física e Desportos da Universidade Federal de Santa Maria. Santa Maria: UFSM; CEFD, 1997.

\section{Como citar este artigo}

GOULART, V. P. C. CEFD/UFSM - 50 ANOS - Uma trajetória pessoal - Com a palavra, Cyro Knackfuss. Revista Kinesis, santa Maria, Dossiê CEFD 50 anos, p.1-08, 2020.

*O presente trabalho não contou com apoio financeiro de nenhuma natureza para sua realização. 